C-02-2020

\title{
TRATAMIENTO ECOLÓGICO PARA LA EUTROFIZACIÓN Y LA ANOXIA EN LAS BALSAS DE RIEGO
}

\begin{abstract}
Mateos-Aparici Baixauli, Ricardo ${ }^{1}(P)$
1 CEO, Socio fundador de Sewervac Ibérica S.L. Empresa de innovación y soluciones hidráulicas y medioambientales ricardo@sewervac.es

\section{Resumen}

Las balsas de riego están expuestas a numerosas problemáticas, la mayoría de ellas relacionadas con la calidad del agua. Es crucial solucionar los problemas acontecidos de una manera natural y respetuosa con el medio ambiente. Mediante la combinación de la aireación natural en el fondo de la balsa y la biorremediación se puede avanzar notablemente en la mejora de la calidad de la masa de agua. Es importante realizar estudios individualizados para cada proyecto con el fin de ajustar la solución a las necesidades particulares de cada balsa de riego.
\end{abstract}

\section{1) Introducción. Objetivo del Trabajo.}

Nuestra empresa Sewervac, comprende diferentes divisiones, una de ellas Oxi-fuch ${ }^{\circ}$, sus experiencias, avances e investigaciones en este campo son el motivo del desarrollo de este artículo. El motivo por el que nos préstamos al desarrollo de este artículo es la propia esencia de nuestra empresa: ser especialistas en ingeniería, soluciones hidráulicas y medioambientales poco difundidas en el mercado, trabajando en estos campos con profesionales con más de 20 años de experiencia en el sector. Además nuestras líneas de trabajo pretenden aportar, al entorno donde se aplican, garantías ambientales con los más altos estándares de exigencia.

La fuente del agua puede ser muy diversa, embalses, pozos, canales...con mayor o menor concentración de nutrientes, turbidez o concentración de desechos. El agua se ha tratado de múltiples maneras tratando de encontrar una solución global a todos los problemas, pero es importante conocer la peculiaridad de cada balsa, y aprender que la masa del agua es un ser vivo y por lo tanto hay que tratar cada situación de manera individualizada. Las soluciones que se proponen son siempre naturales y respetuosas con el medio ambiente, al mismo tiempo que son económicas y sencillas de instalar. La eliminación de algas, problemas de filtrados, fangos, etc. requieren de soluciones que se puedan adaptar y sean flexibles para cada periodo de tiempo.

El objetivo de este trabajo es mostrar como la aireación natural y la biorremediación son capaces de alcanzar grandes porcentajes de éxito, siempre y cuando se lleve a cabo mediante un estudio especializado de la problemática, casuística de la balsa y un adecuado seguimiento.

DOI:10.31428/10317/8715 


\title{
2) Descripción del tema y del proceso de ejecución del Trabajo lo más completa posible
}

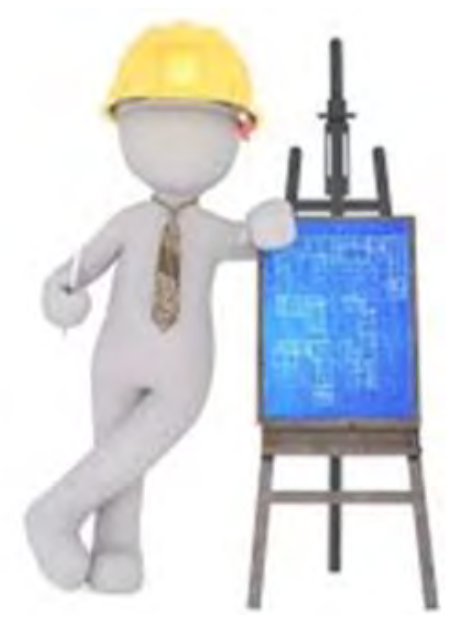

\begin{abstract}
Oxi-fuch ${ }^{\circledR}$ trata de buscar la eficiencia y productividad, planificando desde el lecho de la balsa, para mejorar la calidad del agua y prevenir la eutrofización, al menor coste económico y medioambiental.
\end{abstract}

Necesitamos actuar sobre el origen del problema no sobre sus consecuencias como hasta ahora. El origen es la falta de oxígeno en el agua de la balsa.

Con nuestra aireación profunda se consigue homogeneizar el agua, teniendo la misma composición sin importar la profundidad o longitud de la balsa de riego. Esto previene la formación de estratos y con ello la aparición de varias zonas diferenciadas por la cantidad de oxígeno disuelto en ellas.

Proporcionamos oxígeno, sustancia que necesitan las bacterias para descomponer la materia orgánica y que no se acumulen los fangos en el fondo. De esta manera se evitan malos olores y acumulación de sedimentos y fangos alrededor de la zona anaerobia causantes de la obturación de los filtros impidiendo el paso del agua. Además estas bacterias también consumen los nutrientes que necesitan las algas, dejándolas sin "alimento" y previniendo su aparición. Con nuestra aireación profunda conseguiremos tener unos filtros sin obturaciones y en buen estado, mejorando la calidad del agua y previniendo la eutrofización.

La aireación natural se emplea para obtener unos niveles mínimos, constantes y homogéneos de oxígeno en toda la masa del agua. A partir de un compresor de aire nuestra tecnología de tuberías especiales desarrolla de aireación, suministrando micro burbujas desde el fondo de la balsa. Frente a problemas de contaminación, resistencia, etc. es importante que seleccionemos un sistema de tuberías de aireación con altos niveles de calidad. Debe ir lastrada para que se deposite en el fondo de la balsa y de esta manera crear cortinas de aireación verticales a lo largo de la balsa de agua.

El cálculo de la aireación de la masa de agua se realiza a partir de la necesidad que tenga cada ecosistema. Como parámetros principales se necesita una analítica del agua, DQO y DBO principalmente, así como saber la tasa de renovación del agua y el dimensionado de la balsa de regadío. El compresor y el colector también deben ser diseñados acorde a cada proyecto en cuestión, adaptándose a las necesidades de cada balsa y aportando fiabilidad y eficacia a la solución.

El lastre de la tubería de aireación debe ser natural dejando atrás los inicios donde se pudieran aplicar materiales que puedan producir contaminación o ser perjudicial para el ecosistema. También es muy importante trabajar a la mínima presión dado que serán pérdidas que repercutirán en un menor consumo energético-eléctrico.

Es importante a la hora de diseñar la solución tener en cuenta diferentes aspectos técnicos como la transferencia de oxígeno en la columna del agua, la variabilidad de la temperatura, el consumo de oxígeno de los microorganismos presentes o la transferencia de oxígeno efectiva en relación a la saturación que tenga en cada momento el agua.

No todo es airear-oxigenar.

DOI: $10.31428 / 10317 / 8715$ 


\section{Existen riesgos - exigencias al diseñador.}

- Correcta elección de compresores: relación horas-vida útil.

- Consumos energéticos equilibrados.

- Homogeneización de la masa del agua.

- Factores de hidrodinámica.

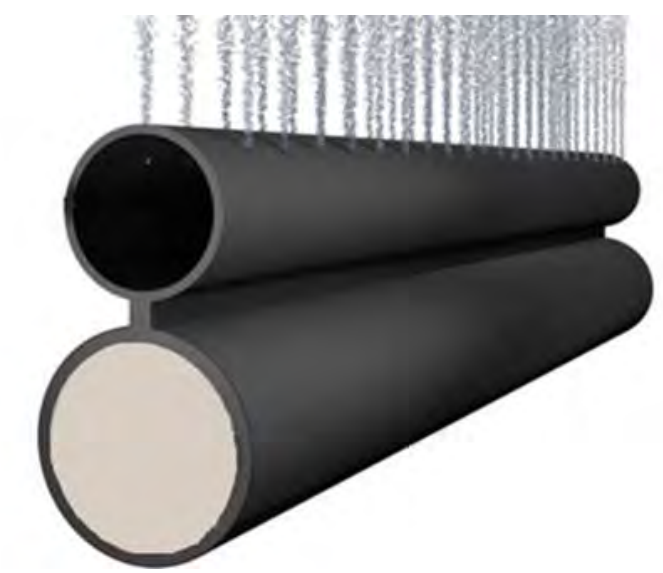

Tubería con arena de sílice lastrada

\section{Recomendaciones y consideraciones relevantes a la hora de seleccionar sistemas de} tubería de aireación.

- Máxima flexibilidad para una mejor adaptación al perfil profundo.

- Que disponga de máxima capacidad de aireación con doble columna de burbuja e incluso posibilidad de perforaciones en ambos tubos.

- Que su vida útil no sea menor a 10 años.

- Que sea resistente a retorcimientos en momentos de posibles desmontajes, limpiezas...

- Que su presión de trabajo sea baja marcándonos como un ideal 0,34 atm.

- Que pueda tener resistencia al Ozono 0-5 ppm frente algún posible tratamiento específico.

- Que disponga de una máxima elasticidad frente a cambios de temperatura.

- Evitar productos de relleno para el lastre, que no sean totalmente naturales, lo ideal es arena de sílice o derivados.

- Que sea $100 \%$ orgánico y respetuoso con el medio ambiente.

- Que sea capaz de tener una alta resistencia a ácidos, gases y a los rayos ultravioleta.

- Que permita la regulación del PH.

- Que sea resistente frente a bacterias.

- Que las perforaciones se cierren cuando se corte la fuente de alimentación por lo que el agua no pueda penetrar dentro de la tubería y deteriorar la futura efectividad de la aireación.

- Mantener una distribución de las perforaciones cada 1/4" que proporcionen burbujas pequeñas y uniformes para una aireación más efectiva que aseguren la máxima transferencia de oxígeno. 
Una vez hayamos tenido en cuenta las recomendaciones expuestas, nos podremos encontrar con beneficios como:

- Reducción de algas

- Mejora del mantenimiento del sistema de filtrado eliminando obturaciones.

- Reducción de los volúmenes de fango y sedimentos del fondo.

- Eliminación de olores.

- Eliminación de termoclinas.

- Rotura de la tensión superficial previniendo las plagas de insectos.

- Aumento de oxigeno tanto en el sedimento como en las masas de agua.

- Eliminación de los componentes orgánicos.

- Eliminación del tratamiento mediante químicos.

\section{BENEFICIOS PARA LOS CULTIVOS:}

La concentración necesaria de oxígeno para que un suelo esté bien aireado es del $\mathbf{2 0 , 7 \%}$, con concentraciones por debajo del $\mathbf{1 0 - 1 5 \%}$ algunas plantas inhiben su crecimiento ocasionando grandes pérdidas económicas.

- Más crecimiento: En la mayoría de plantas la transferencia de oxígeno no alcanza una tasa suficiente. Por este motivo, en suelos con condiciones físicas desfavorables, la aireación es necesaria para aportar concentraciones suficientes de oxígeno a la zona radicular.

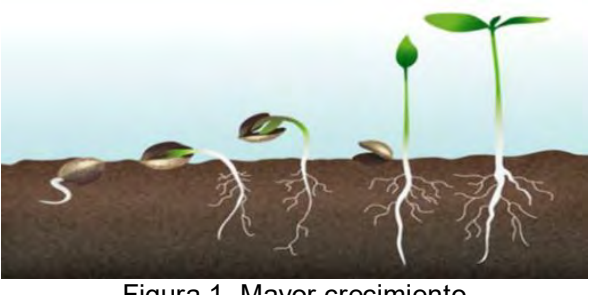

Figura 1. Mayor crecimiento

- Más Beneficio: El rendimiento de la producción aumenta de forma notable cumpliendo el ciclo de maduración en menor espacio de tiempo de lo habitual. Una cosecha más voluminosa y un cultivo más productivo, conseguido en menor cantidad de días, ahorrando gran cantidad de agua de riego, gastos de abonos y otros aditivos.

- Mejor sabor: Otra factor a destacar es la calidad del sabor de los productos que contendrán una mayor cantidad de azúcares.

- Cultivo ecológico: Tecnología natural, sin componentes tóxicos o contaminantes, que permite el cultivo ecológico sin necesidad de usar químicos u otros productos que además no resuelven el problema en su origen.

\section{Los receptores de sistemas de aireación deben solicitar:}

- Una justificación técnica del diseño de diámetros y equipos.

- Una justificación de sistemas de control de la eficiencia teniendo un consumo energético adecuado al problema, aunque este sea cambiante.

- Seguimiento y acompañamiento. 
- Es importante realizar una correcta planificación del fondo, podemos construir soluciones a modo de caño de aire o disco, en nuestro caso las empleábamos en el pasado, aunque las podemos seguir aportando al mercado, pero pronto pudimos observar su poca eficiencia. Inicialmente eran más económicas en su valor unitario, pero al trasladar su caudal de aire frente a la eficiencia, observamos que eran necesarios muchas más unidades de estos elementos para igualar la implantación homogénea.

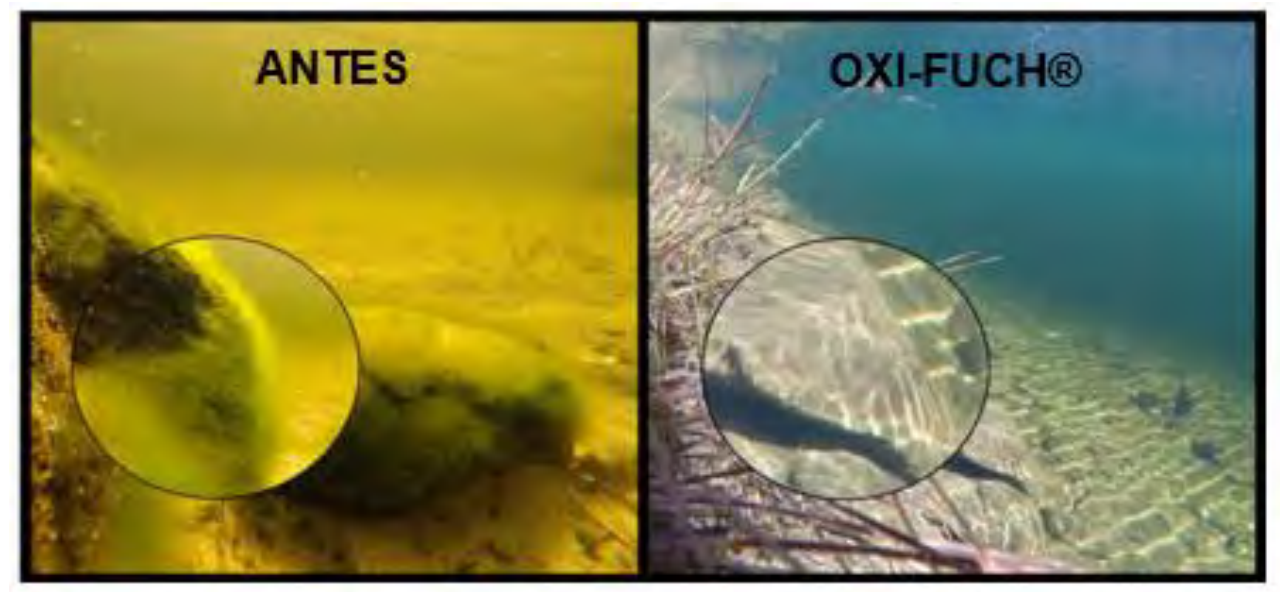

\section{Biorremediación}

En cuanto a la biorremediación, se trata de revertir el equilibrio actual del ecosistema. Mediante el empleo de diferentes microorganismos/bacterias se consigue una competencia directa y natural con las algas, lo que favorecerá su desaparición. Los microorganismos deben pertenecer al grupo 1 de la Unión Europea, no habiendo sido modificados genéticamente ni alterados en un laboratorio.

El método de aplicación de las bacterias es crucial para la eficacia de dicha solución. Los microorganismos son seres vivos y por lo tanto necesitan un hábitat adecuado y estable. La aclimatación del producto, previa a su dosificación, es fundamental para eliminar la problemática de cada lugar.

Hay diferentes cepas de microorganismos con multitud de aplicaciones. Es por ello que la especificidad y el empleo de las bacterias adecuadas para cada problemática son de gran relevancia en la efectividad de la solución. Las cepas de microorganismos difieren en su tasa de duplicación, en la cantidad de microorganismos o el ratio de alimentación, por lo que deben de tenerse en cuenta todos estos aspectos técnicos a la hora de abordar la solución. Entre las más destacadas se encuentran las bacterias encargadas de eliminar los nutrientes presentes en el agua de la balsa y degradar el fango.

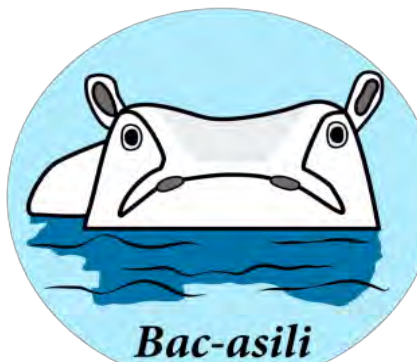

Bac-asili

Bac-asili es otra división de la empresa Sewervac, que aprovecha el poder de la biotecnología medioambiental para resolver el problema degradando la materia orgánica y utilizando los nutrientes de forma altamente eficiente.

Emplea bacterias naturales y específicas que son beneficiosas. Se caracteriza por el diseño de bacterias individualizadas para los sectores del riego, masas de agua, depuradoras o bombeos de agua residual. 
Las bacterias deben de haber sido desarrolladas específicamente para los problemas de las balsas, principalmente acumulación de fangos y algas.

Se debe usar sólo microorganismos naturales e inofensivos para lidiar con el problema, que se encarguen de degradar la materia orgánica, convertirla en $\mathrm{CO} 2$ y $\mathrm{H} 2 \mathrm{O}$ y eliminar los nutrientes inorgánicos, especialmente el amoniaco, nitrito, nitrato y fosfato, de forma altamente efectiva y medioambientalmente respetuosa.

Por otra parte, deben contener una mezcla cuidadosamente seleccionada de microorganismos naturales que tengan la habilidad de degradar materia orgánica eficientemente y consumir el exceso de nutrientes que dan lugar a la proliferación de algas.

Estos microorganismos utilizan los nutrientes disponibles, dejando a las algas sin "alimento". Esto ayuda a mejorar la calidad del agua aumentando el nivel de oxígeno disuelto.

Este método de control biológico ayuda a restablecer el equilibrio natural y ecológico del ecosistema acuático.

Algunas de las cepas de este producto pueden funcionar en condiciones en las que el oxígeno está limitado.

En definitiva la biorremediación que os presentamos, es una solución con un gran desarrollo tecnológico y que necesita de unas condiciones mínimas para asegurar una mínima eficacia. La situación ideal es aplicarlas en balsas donde te asegures que haya una concentración mínima y constante de oxígeno disuelto en el agua.

\section{3) Conclusiones, Resultados...}

Los resultados de ambas tecnologías son: ecosistemas más ricos y estables; y mejor calidad del agua de las balsas de regadío.

La aireación favorece la competencia de los microorganismos presentes en el agua frente a las algas. Favorece una degradación aerobia del fango, eliminando malos olores y mejorando el estado de los filtros. Reduce la dureza del agua mediante la oxidación de determinados compuestos. Incrementa el sabor y riqueza de los productos al tener una mayor concentración de oxígeno. Homogeneiza la masa del agua, elimina termoclinas. En general una masa de agua rica en oxígeno es un agua de alta calidad.

El uso de microorganismos sirve para incrementar la degradación del fango o para ayudar a crear una competencia mayor a las algas de una manera natural y respetuosa con el medio ambiente.

La combinación de ambas tecnologías busca una mayor eficacia en la respuesta englobando todas las características técnicas que hay que analizar a la hora de solucionar los problemas que sufren las diferentes masas de agua.

La aplicación de soluciones en la agricultura tiene que tener como prioridad el respeto al medio ambiente. Las soluciones tienen que ser naturales, alejadas del uso de soluciones que ataquen a la consecuencia del problema y no a la causa que es, en la mayoría de casos, una concentración reducida de oxígeno.

Es muy importante analizar cada caso como único y específico para poder dar la respuesta más adecuada a cada problemática.

No existe una solución única y global, es necesario analizar, consultar y estudiar cada escenario ofreciendo las herramientas necesarias para dar solución a los problemas de cada balsa. Además de un seguimiento continuado y que permita adaptaciones a nuevos escenarios. 


\section{Satisfacción-consejos:}

No nos tenemos que dejar llevar tan solo por una primera impresión al ver que se ha dejado de tener algún problema en filtros o desaparición de algas.

Si como lector de este artículo eres un posible receptor de un sistema de oxigenación o biorremediación, usted debe asumir que con su balsa se encuentra ante (buscando un simil) un enfermo que tiene unas determinadas patologías, además crónicas, que los parámetros de la química del agua son cambiantes y que por lo tanto requerirá de un adecuado seguimiento que permita observar la evolución e ir tomando nuevas medidas, si así se requiriese, para mantener el equilibrio deseado. Es decir, su balsa o ecosistema es un ser vivo, sensible y que necesita un seguimiento. En el agua no existe la magia. Le sugerimos que realice un adecuado análisis en su toma de decisiones técnicas y objetivas junto a un seguimiento de los consumos energéticos frente a la calidad del agua.

DOI:10.31428/10317/8715 